\title{
Urban Trypanosoma cruzi Oral Transmission: from a Zoonotic Founder Focus to the Largest Microepidemic of Chagas Disease
}

\author{
Díaz-Bello Z ${ }^{1 *}$, Zavala-Jaspe $\mathrm{R}^{1}$, Reyes-Lugo $\mathbf{M}^{2}$, Colmenares $\mathrm{C}^{1}$, Noya-Alarcón $\mathbf{0}^{3}$, Noya $\mathbf{0}^{4,5,7}$, \\ Herrera $L^{6}$ and Alarcón de Noya $B^{1,5 *}$ \\ ${ }^{1}$ Sección de Inmunología \\ ${ }^{2}$ Sección de Entomología. \\ ${ }^{3}$ Sección de Ecología Parasitaria \\ ${ }^{4}$ Sección de Biohelmintiasis, Instituto de Medicina Tropical, Facultad de Medicina. \\ ${ }^{5}$ Cátedra de Parasitología "Escuela Luis Razetti" \\ ${ }^{6}$ Laboratorio de parásitos y vectores, Instituto de Zoología y Ecología Tropical, Facultad de Ciencias; Universidad Central de Venezuela, Caracas, Venezuela \\ ${ }^{7}$ Centro para Estudios sobre Malaria, Instituto de Altos Estudios “Dr. Arnoldo Gabaldón", MPPS - Instituto Nacional de Higiene "Rafael Rangel”, MPPS
}

Received: March 28, 2016; Accepted: May 12, 2016; Published: May 17, 2016

*Corresponding author: Zoraida Díaz-Bello and Belkisyolé Alarcón de Noya, Instituto de Medicina Tropical, Universidad Central de Venezuela, Código Postal 1041, Los Chaguaramos, Caracas, Venezuela, E-mail: zoraida_diaz@yahoo.com; belkisuole@gmail.com

\begin{abstract}
The American Trypanosomiasis or Chagas' disease is a complex zoonosis that involves biological, sociocultural, economics and politics particularities. A great number of mammal reservoirs and triatomine vectors take part in Trypanosoma cruzi chain transmission. Humans have increased their contact focus in the nature, causing an ecological disturb and allowing triatomines to visit and colonize human dwellings. In these new niches, triatomines found a shelter and a food source in local synanthropic mammals and humans. The oral transmission of T. cruzi seems to be much more common than it is believed in the endemic cycle through food chains in mammals that prey vectors and other infected mammals. The purpose of this study was to define and characterize the initial focus from an outbreak of Chagas' disease attributed to oral transmission occurred in Caracas, Venezuela. Trypanosoma cruzi research was performed in triatomines and reservoirs captured in the area where the homemade preparation of contaminated juices destined to scholarship consumption took place. Biological and molecular characterizations of Trypanosoma cruzi isolates were made from $52.6 \%$ of triatomines, $40 \%$ of rats and $66 \%$ of dogs, which resulted in Trypanosoma cruzi positive. All the evidence suggests that the potential starting focus was approximately $6.7 \mathrm{Km}$ far away from the school where the oral outbreak occurred, and it reveals the existence of a local micro focus of $T$. cruzi transmission between rats and triatomines with eventual human participation who get infected via oral route.
\end{abstract}

Keywords: Chagas disease; Trypanosoma cruzi; Panstrongylus geniculatus; Rattus rattus; Oral transmission; Zoonotic focus

\section{Introduction}

American Trypanosomiasis is a parasitic infection typical from rural or suburban areas, where structural and qualitative deficiencies of human dwelling, surrounding by a very rich flora and fauna environment allow contact with wild triatomines [14]. The human infection by Trypanosoma cruzi is a very complex zoonosis by its biological, ecological, socio-cultural, economic and political particularities. The chain of transmission involves a large number of reservoirs and triatomine vectors. Deforestation, urbanization and other environmental interventions decrease triatomine food sources forcing them to invade houses or to live in the peridomiciliary space, feeding during the night on the inhabitants, domestic and synanthropic animals [5]. Up until now, 180 species have been identified as reservoirs included in Artiodactyla, Carnivora, Cingulata, Chiroptera, Didelphimorphia, Lagomorpha, Perissodactyla, Pilosa, Primates (including man), and Rodentia orders [5]. The existence of the human Chagas disease is accidental, in the measured in that man was coming in contact with natural foci and caused ecological imbalances.

The genus Panstrongylus (Hemiptera, Reduviidae, Triatominae,) and more specifically, $P$. geniculatus, $P$. megistus and $P$. rufotuberculatus has shown a great adaptable plasticity that allows it to occupy human dwellings [6,7]. P. geniculatus, Latreille 1811 is widely distributed in America, from southern Mexico to northern Argentina. Domiciliation by these triatominos, including urban places, is known [8-12]. Foci of T. cruzi in the valley of Caracas and its potential reservoirs and vectors are known since Quintini J [13].

Didelphis marsupialis is the most important synanthropic reservoir of the continent due to its wide geographical distribution, high levels of natural infection with T. cruzi and the presence of infective metacyclic trypomastigotes in the perianal glands similar to vector infective trypomastigotes, being highly infectious through oral, nasal, ocular routes or skin wounds and abrasions $[14,15]$.

In some localized areas of Latin America, T. cruzi human infection is actually considered to be emerging due to changes 
in human behavior and ecology, resulting in the transmission cycle gaining a foothold in urban areas [16]. Alterations to the environments surrounding towns and cities resulted in the establishment of urban enzootic foci of T. cruzi $[17,18]$.

Since 1991, several subregional initiatives have made major advances in decreasing vector infestation in human dwellings and extending screening of the blood supply for T. cruzi $[19,20]$. In 2007, control efforts in Latin America were formally joined by an initiative to address the "globalization" of Chagas disease, recognizing the increasing presence of imported cases in Europe, North America, and Japan and the potential for local transmission through non-vectorial routes [21]. The United States occupies an undefined position in this new initiative. While the United States has never participated in Latin American Chagas disease control programs, it cannot be classified as an area where the disease is "not endemic" in the same sense as Europe or Japan. The southern tier of states from Georgia to California contains established enzootic cycles of T. cruzi, involving several triatomine vector species and mammalian hosts such as raccoons, opossums, and domestic dogs [22,23].

The microepidemic of Chagas disease in an urban school in Chacao, Caracas, and the largest oral transmission ever documented in South America has raised awareness about the reappearance of an old problem known in the capital city [2426]. The same supplier of other municipal schools provided the food and beverages consumed by students and school personnel, with the exception of breakfast, which includes home-made juices prepared under other health conditions, more specifically in a house located in a neighborhood on the western hillside of Caracas city at $6.7 \mathrm{~km}$ away from the school. In order to characterize of zoonotic founder focus, we have studied the vectors and mammals in the home-made factory of fruit juice so it could be recognized as the focus origin of the mentioned oral transmission outbreak.

\section{Materials and Methods}

\section{Study area}

The first research in the home-made factory juices and surroundings was held three months after Chagas disease outbreak in Chacao municipality [26]. Caracas is a megalopolis of $1,200 \mathrm{~km}^{2}$, located among the mountains of Vargas coast and the "Sierra Maestra" mountains $\left(10^{\circ} 21^{\prime}-10^{\circ} 32^{\prime}\right.$ N, 66 $46^{\circ}$ ' $66^{\circ} 58^{\prime}$ $\mathrm{W})$, which has an intertropical warm climate. The precipitation ranges between 900 to $2000 \mathrm{~mm}$ per year, and its annual temperature is $22.5^{\circ} \mathrm{C}$, the coldest month (January) is $21^{\circ} \mathrm{C}$ and the warmest (May) is $24^{\circ} \mathrm{C}$. Relative humidity is $70 \%$. The last census (2011) registered a population of 3.055.000.

\section{Triatomine Survey}

The home-made juice factory (Figure 1), referred to in the present work is located in the parish of Altagracia, Libertador municipality - Tamarindo sector, which is surrounded by herbaceous vegetation, trees, palm trees, and other houses. This site is $0.9 \mathrm{~km}$ away from Waraira Repano National Park.

During the first visit to El Tamarindo, a meeting was held in

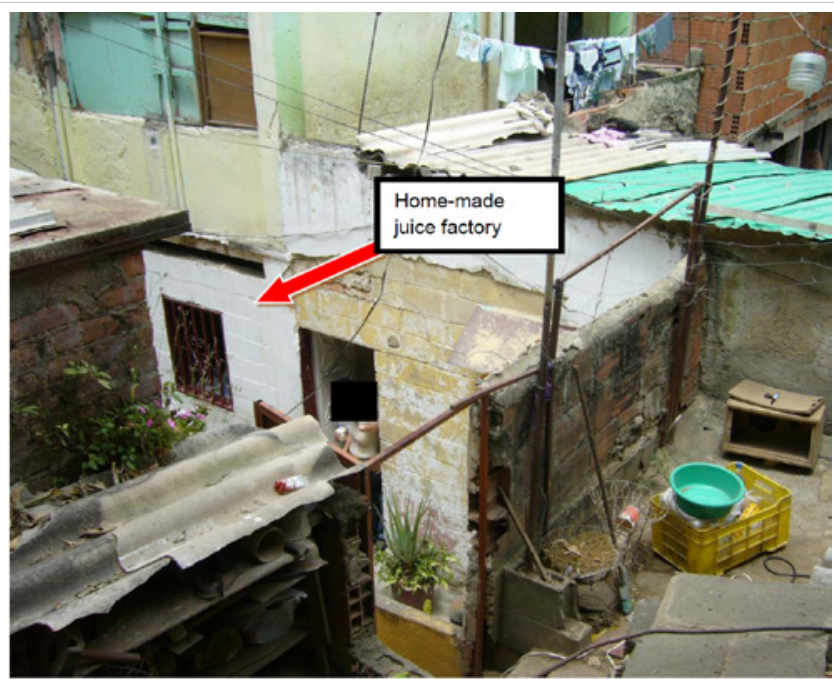

Figure 1: The house and the surroundings where juices were prepared in the Chacao outbreak.

the community to raise their awareness about the disease and its mode of transmission. Bugs and reservoirs were sampled in a ten-meter diameter considering the home-made juice factory as the central point, which includes about 20 nearby houses and vegetation zones.

The triatomine collection was carried out by two methods. An active search for triatomines (4 man/ hour) was performed, revising every place: walls, crevices, beds, mattresses, clothes boxes etc., and the voluntary collection by the inhabitants. Triatomines were collected using flashlights and tweezers; they were transported in containers until the laboratory. A previous training to ensure the protocol and management of insects was carried out in the community. Small cardboard boxes were identified taking note of the name, date, place and time of capture, and were used and collected in a large box stored in a warehouse. Every three days, big boxes were taken to the laboratory. The collection was carried out for two months.

The triatomines were dissected in sterile isotonic saline to microscopically examine fresh smear of the intestinal content. (400X), searching for trypanosomes. The intestinal content was divided into 2 parts. A part of the feces of the triatomine was observed in a phase contrast microscope. Each T. cruzi positive intestinal content was intraperitoneally inoculated in 5 isogenic male mice (NMRI strain) $13 \mathrm{~g}$ body weight, in proportion of 200 metacyclic form/g body wt. Animals were checked every three days searching for trypomastigotes morphologically compatible with T. cruzi and parasites were quantified by Brener method [27]. Natural T. cruzi infection index (NII = Number of T. cruziinfected triatomines / number of triatomines tested x 100) in collected triatomines was calculated according to WHO [28].

Other part of the stool of collected triatomines was used to determine the eating pattern.

\section{Mammals survey}

Xenodiagnosis was conducted with 20 stage III nymphs in all 
animals captured. A random sampling of mammals in Tamarindo Sector was conducted with 17 wire mesh traps, (Tomahawk live traps Co. Tomahawk, Wisconsin, USA, Mod 204, 50.8 x $17.9 \times$ 17. $9 \mathrm{~cm}$ ) and 6 "Sherman" traps (Tomahawk live traps Co, Mod $101,25.4 \times 7.6 \times 7.6 \mathrm{~cm}$ ) (Figure 2). The traps with universal bait were placed at $2 \mathrm{~m}$ away from the houses, in an 8-m wide $\times 2 \mathrm{~m}$ (between traps) transect. From the tail vein of captured animals a blood sample was taken for microscopically observation and additionally used for serological diagnosis to T. cruzi by ELISA test. Parasites from blood were cultured on blood agar medium.

Dogs were sampled with xenodiagnosis as described, prior consent by owners. Blood was not taken directly from these animals because their owners did not allow sampling them with syringes. Instead, one triatomine used in the xenodiagnosis was utilized as a natural syringe and the blood was afterward place on filter paper. ELISA was performed with the elution of the blood from the filter paper.

\section{Feeding pattern of triatomines}

In order to identify the origin of blood-meal of collected triatomines, an Immunosorbent Assay Was performed on a Paper Adhered to Plastic (IESPAP) [29]. Briefly, $5 \mu$ of triatomine feces is placed on a 3-mm bond paper, attached with cement paste to each tooth of an 8-tooth plastic comb; it was allowed to dry overnight at $4^{\circ} \mathrm{C}$.

Then, $5 \mu \mathrm{l}$ of $5 \%$ albumin was added to paper disc and incubated for 2 hours at $20^{\circ} \mathrm{C}$. Antisera, $150 \mu \mathrm{l}$, from different animals (dog, rat, mouse, cat, bird, man, Didelphis sp.) conjugated to alkaline phosphatase and diluted in PBS pH 7, 0.05\%. Tween 20 and 5\% skim milk were placed in 96 wells plate. Combs with the paper discs previously sensitized with feces were inserted into the respective wells. From this step, all reactions were

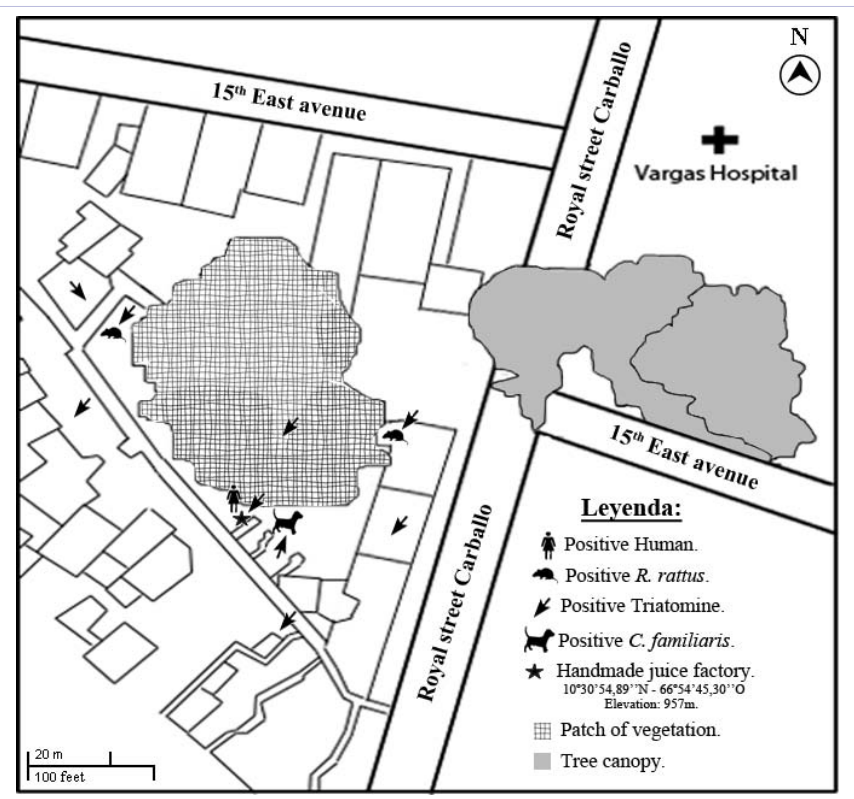

Figure 2: Location of the central house (black star: home-made juice factory) and infected triatomines, reservoirs and mammals including humans with Trypanosoma cruzi. carried out on the plate. After Incubation for $40 \mathrm{~min}$ at $37^{\circ} \mathrm{C}$, the paper disks were washed with a washing solution (PBS pH 7.2 with $0.05 \%$ Tween 20 ) using a wash bottle. 100 ul per well of p-nitrophenyl phosphate in Diethanolamine (DEA) $(1 \mathrm{mg} / \mathrm{ml})$ is placed in a flat bottom plate. The combs are inserted into the plate and incubated at $37^{\circ} \mathrm{C}$ for 20 minutes. After removing the combs, the reaction was stop with $100 \mu \mathrm{l}$ of $1 \mathrm{M} \mathrm{NaOH}$ and read at $405 \mathrm{~nm}$.

\section{Immunological diagnosis of Trypanosoma cruzi in reservoirs}

The presence of IgG-ELISA was performed according to Voller, et al. [30] modified by Díaz-Bello, et al. [31]. Maxisorp (Nunc) polystyrene plates were sensitized with $T$. cruzi epimastigotes isolated antigen $1593(15 \mu \mathrm{g} / \mathrm{ml})$ at $4{ }^{\circ} \mathrm{C}$ overnight and washed with PBS-Tween-20 0.05\% v/ v. Subsequently, $100 \mu \mathrm{L}$ of serum dilution solution (PBS pH 7.2, Tween-20 0.05\% 5\% skim milk) was added to $3 \mathrm{~mm}$ discs of filter paper with the blood of studied animals. When serum was available, $50 \mu \mathrm{L}$ of a dilution of $1 / 100$ was placed in each well of the plate and incubated for 45 minutes at $37^{\circ} \mathrm{C}$. Then the anti-IgG conjugated to alkaline phosphatase was diluted $1 / 1000$ and 50 ul was added to each well incubated for 45 minutes at $37^{\circ} \mathrm{C}$. After this time the plate was washed 3 times and p-nitrophenyl phosphate $(1 \mathrm{mg} / \mathrm{ml})$ diluted in DEA buffer $\mathrm{pH}$ 9.6. The reaction was stopped after $15 \mathrm{~min}$. with $1 \mathrm{M}$ $\mathrm{NaOH}$ and read at $405 \mathrm{~nm}$.

\section{Molecular characterization of T. cruzi isolates}

T. cruzi isolates from triatomines and rats collected and 12 orally infected patients of "Andrés Bello" School were characterized. Two techniques were used to describe the lineages of T. cruzi according to Souto, et al. [32]. In summary, we used $25 \mu \mathrm{L}$ of PCR reaction mixture containing $2.5 \mathrm{mM}$ of each dNTP, $100 \mathrm{pmol}$ of a primer mini-exon: TC (CCCCCCTCCCAGGCCACACTG), TC1 (GTGTCCGCCACCTCCTTCGGGCC) and TC2 (CCTGCAGGCACACGTGTGTGTG), $2.5 \mathrm{U}$ of Taq DNA polymerase (Gibco Life Technologies), $100 \mathrm{ng}$ of DNA extracted from each selected isolates, all in buffer $50 \mathrm{mM} \mathrm{KCl}, 10 \mathrm{mM}$ Tris $\mathrm{HCl}$, pH 8.8 with $1.5 \mathrm{mM} \mathrm{MgCl}$. Amplification was performed in a thermo cycler (MJ Research PTC-200) under the following conditions: $94^{\circ} \mathrm{C}$ for $1 \mathrm{~min}, 27$ cycles at $94^{\circ} \mathrm{C}$ for $30 \mathrm{sec}, 55^{\circ} \mathrm{C}$ for $30 \mathrm{sec}, 72^{\circ} \mathrm{C}$ for $30 \mathrm{secs}$, and finally $72^{\circ} \mathrm{C}$ for $5 \mathrm{~min}$. The second technique used was the amplification of $24 \mathrm{~S}$ ribosomal subunit gene with the D71 (AAGGTGCGTCGACAGTGTGG) and D72 (TTTTCAGAATGGCCAACAGT) for a final PCR reaction mixture volume of $25 \mu \mathrm{l}$ and describe conditions amplification was performed in a thermocycler (MJ Research PTC-200): $94^{\circ} \mathrm{C}$ for $4 \mathrm{~min}, 30$ cycles at $94^{\circ} \mathrm{C}$ for $1 \mathrm{~min}, 60^{\circ} \mathrm{C}$ for $1 \mathrm{~min}, 72^{\circ} \mathrm{C}$ for $1 \mathrm{~min}$, and finally $72^{\circ} \mathrm{C}$ for $5 \mathrm{~min}$. The negative control for each PCR reaction included all reaction components except template DNA or sample, which will be replaced with sterile Milli Q water.

PCR products were separated by agarose gel electrophoresis Ultra Pure (Gibco Life Technologies) to $2.5 \%$ and at $80 \mathrm{~V}$ for 2 hours; the bands were observed by using ethidium bromide stain $(10 \mathrm{mg} / \mathrm{ml})$ on a trans-illuminator FBTIV Fisher Biotech (Fisher Scientific). The size of the amplification products were determined by comparing it to a standard pattern of linear 
double-stranded DNA between $100 \mathrm{bp}$ to $1 \mathrm{~kb}$ (1 kb DNA ladder, Gibco Life Technologies). The results were documented by using a Kodak camera coupled to computerized photograph KODAK 1D.

\section{Results}

People of the "El Tamarindo" community had been living in the area for about 1-60 years and the average time is $31.1+/$ 20.6 years. The larger families were constituted by 12 members and $56 \%$ of inhabitants they had pets as dogs, cats, rabbits, parrots, tortoises, birds and pigs. They have seen many rats and mice but no Didelphis.

Eighty-nine per cent of human dwellings had zinc roof, cement floors and block walls, $100 \%$ have electricity service, water, and sewer systems for wastewater collection, $67 \%$ had garbage collection system. Seventy-seven percent of people reported having seen vectors in their homes. The entomological survey revealed the presence of bugs in the houses, with a frequency of 9 to 10 triatomines per week.

The distribution of the home-made juice factory, the positive triatomine ( $P$. geniculatus), and the infected mammals with Trypanosoma cruzi (including an infected human, the one who prepared the fruit juices) are shown in Figure 2.

In a ten-meter diameter area to the central house, 78 adults $P$. geniculatus were found, 77 captured by community participation during two months in kitchens, living rooms and bedrooms of the houses and 1 specimen with a 4 man/hours/day capture effort in the "patio" of the main house. Triatomine nymphs were not found.

The only triatomine collected during home visits was found in the dog house ( $3 \mathrm{~m}$ away from central house). T. cruzi was found in $52.6 \%(41 / 78)$ of examined P. geniculatus, without statistically significant difference between the rates of infection for males or females $(p=0.11)$ and containing $2 \times 10^{6}$ metacyclic trypomastigotes / $\mathrm{ml}$ of feces (average).

The IESPAP for the identification of triatomine food source was obtained from the intestine content of 57 triatomines from which 48 (84\%) showed reactivity to blood proteins of one or more mammals: mouse $>$ rat $>$ rabbit $>$ bird $>$ cat $>$ dog $>$ human (Table 1). Nourishment source could not be performed in the remaining 9 triatomine contents (16\%), because most were fasting or dead (content was too dry). The IESPAP was considered reactive with the absorbance values ranging from $0.326 \mathrm{~nm}$ to $0.978 \mathrm{~nm}$ (above cut off point 0.320) (Figure 3).

Blood reactivity to mouse, rat and rabbit was the most prevalent (45.6\%, 42.1\% and 35\%, respectively). Human blood was detected in a low proportion (10.5\%) and blood Didelphis $s p$ was not found. The prevalence of mouse and rat blood as food source was equally observed in both sexes of triatomines.

The number of blood meals identified by IESPAP fluctuated as follows: $16 \%$ non-reactive, only one type of blood $24 \%$, two $29.97 \%$, three $12.34 \%$, four $8.8 \%$, five $76 \%$, six $3.52 \%$ and seven $3.53 \%$. Two food sources were the most prevalent, $n=17$ (29.97\%). The technique was able to identify the presence of IgG from 7 different types of vertebrates in the intestine of two $P$. geniculatus. Blood meals from multiple sources were observed in 34 triatomines.

The Infectivity Index of Ingested Blood (IBMI) was > 50\% to all tested antisera (Table 2). It was observed that all specimens' reactive to human, dog and rabbit were positive to $T$. cruzi, followed by rats and mice. Four triatomines were infected with T. cruzi out of the 16 triatomines which did not react to the blood searched.

Table 1: IESPAP identification of mammals nourish source from Panstrongylus geniculatus captured in El Tamarindo-Altagracia $(n=57)$.

\begin{tabular}{|l|l|l|l|l|l|}
\hline Blood meal & $\begin{array}{l}\text { N (number of } \\
\text { exemplars) }\end{array}$ & $\mathbf{\%}$ & Blood meal & $\begin{array}{l}\text { N (number of } \\
\text { exemplars) }\end{array}$ & \% \\
\hline Bird & 2 & 3.50 & Mouse/Rabbit & 2 & 1 \\
\hline Cat & 3 & 5.26 & Bird/Dog/Mouse & 2 & 1.76 \\
\hline Rat & 3 & 5.26 & Cat/Rat/Mouse & 2 & 3.53 \\
\hline Mouse & 3 & 5.26 & Bird/Rat/Rabbit & 1 & 3.53 \\
\hline Rabbit & 3 & 5.26 & Bird/Rat/Mouse & 1 & 1.76 \\
\hline No reactive & 9 & 16.0 & Bird/Mouse/Rabbit & 1 & 1.76 \\
\hline Human/Rat & 1 & Bird/Cat/Mouse/Rabbit & 1 & 1.76 \\
\hline Bird/Cat & 1 & Dog/Cat/Rat/Mouse & 1 & 1.76 \\
\hline Bird/Rat & 1 & 1.76 & Dog/Cat/Rat/Rabbit & 1 & 1.76 \\
\hline Bird/Mouse & 1 & 1.76 & Human/Bird/Rat/Rabbit & 1 & 1.76 \\
\hline Bird/Rabbit & 1 & 1.76 & Bird/Rat/Mouse/Rabbit & 1.76 \\
\hline Dog/Mouse & 2 & 1.76 & Human/Bird/Dog/Cat/Mouse & 1 & 1.76 \\
\hline Cat/Mouse & 2 & 3.53 & Human/Bird/Cat/Rat/Mouse/Rabbit & 1 & 1.76 \\
\hline Rat/Mouse & 3 & 3.53 & Bird/Dog/Cat/Rat/Mouse/Rabbit & & 1.76 \\
\hline Rat/Rabbit & 3 & 5.29 & Human/Bird/Dog/Cat/Rat/Mouse/ & 2 & 3.53 \\
\hline
\end{tabular}




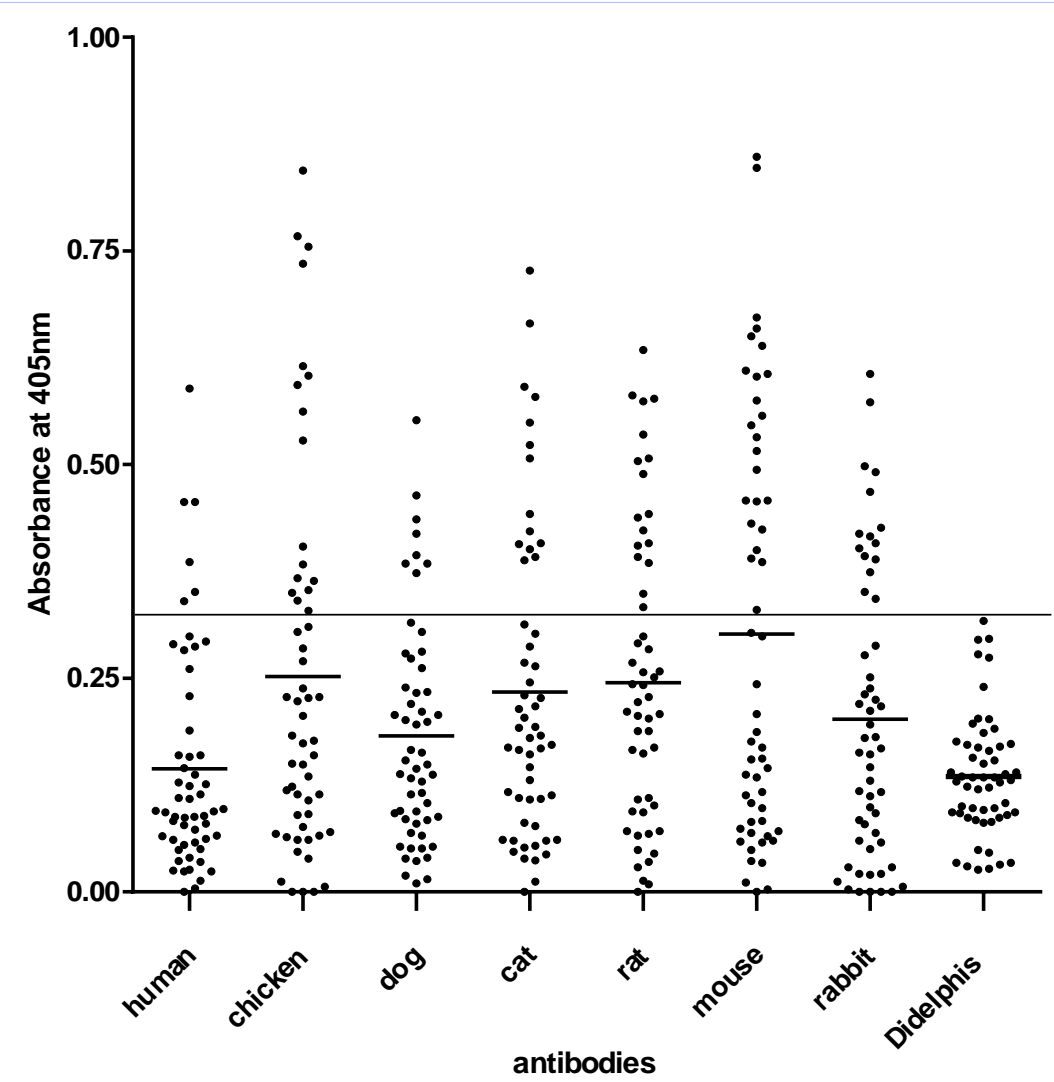

Figure 3: Feeding pattern of Panstrongylus geniculatus captured in El Tamarindo, Altagracia parish in Caracas, 2008. $(\mathrm{n}=57)$.

\begin{tabular}{|c|c|c|c|c|c|c|c|c|}
\hline \multirow[b]{2}{*}{ T. cruzi } & \multirow[b]{2}{*}{ Total evaluated } & \multicolumn{7}{|c|}{ Antisera } \\
\hline & & $\begin{array}{l}\text { Human } \\
\mathrm{n}(\%)\end{array}$ & $\begin{array}{l}\text { Bird } \\
\text { n (\%) }\end{array}$ & \begin{tabular}{|l} 
Dog \\
n (\%)
\end{tabular} & $\begin{array}{l}\text { Cat } \\
\text { n (\%) }\end{array}$ & \begin{tabular}{|l} 
Rat \\
n (\%)
\end{tabular} & $\begin{array}{l}\text { Mouse } \\
\text { n (\%) }\end{array}$ & $\begin{array}{l}\text { Rabbit } \\
\text { n (\%) }\end{array}$ \\
\hline Positive & 31 & $4(12.9)$ & $11(35.5)$ & $6(19.3)$ & $9(29)$ & $15(48.3)$ & $16(51.6)$ & 13(41.9) \\
\hline Negative & 26 & $2(7.7)$ & $8(30.7)$ & $3(11.5)$ & $7(26.9)$ & $9(34.6)$ & $10(38.9)$ & 7 (26.9) \\
\hline IBMI* & & 66.6 & 57.8 & 66.6 & 56.2 & 62.5 & 61.5 & 65 \\
\hline
\end{tabular}

* IBMI= Infectivity Blood Meal Index = (number of T. cruzi positive triatomines fed on host / number of triatomines fed on that host X) $\mathrm{x} 100$.

Looking for T. cruzi, a total of 16 domestic and synanthropic animals were examined. Two domestic rodent species were captured: $10 \mathrm{R}$. rattus and 3 Mus musculus. Three dogs were examined and Didelphis was not captured. The overall prevalence of infection was $37.5 \%$. Of the 10 R. rattus, $40 \%$ were positive for T. cruzi in blood agar and xenodiagnostic and two out of three dogs were reactive by serology, none Mus musculus was positive.

Genetic typing of 47 isolates of T. cruzi (31 triatomines, 4 rats and 12 orally infected patients from "Andrés Bello" School previously isolated) was performed by PCR. As seen in Figure 4, the amplification of non-transcribed intergenic mini-exon gene in a multiplex reaction using primers TC, TC1 and TC2, generated a $350 \mathrm{bp}$ product in all samples of the study and at the Munanta control sample (C2) isolated and characterized as DTU I. No band was generated when a gDNA from an Ikiakora isolate (C1) (a control characterized as DTU TCIII) was used. These results indicate that all the 47 parasite isolates analyzed belong to DTU TCI. These data were confirmed when PCR was performed with specific primers for the amplification of ribosomal subunit $24 \mathrm{~S}$ rRNA and the amplified bands of the expected size for isolated DTU TCI appeared (Figure 4).

\section{Discussion}

Chagas disease is a zoonosis caused by the protozoan Trypanosoma cruzi, mainly transmitted to humans through 


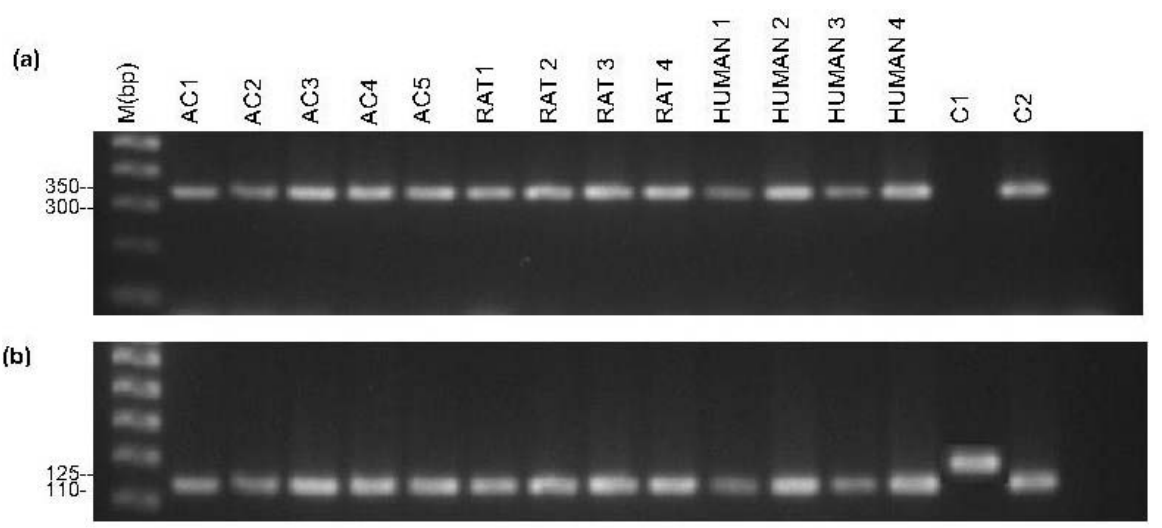

Figure 4: Lineage typing through agarose gel (2\%) electrophoresis of polymerase chain reaction (PCR) products generated by amplification of DNA from isolate of Trypanosoma cruzi from Panstrongylus geniculatus (AC) Rattus rattus (RAT) and human of outbreak Chagas' oral: (a) amplification of mini-exon gene sequences and (b) amplification of 24S $\alpha$-rDNA sequences. DNA from the reference strains Ikiakora and Munantá for $T$. cruzi III and $T$. cruzi I, respectively, used as positive controls.

direct contact with vectors, blood transfusion and congenitally. In certain epidemiological situations, the parasite has shown its ability to orally be carried through the consumption of contaminated food, causing an acute disease outbreak [26,3335].

Aspects associated to the appearance of Chagas' disease in the valley of Caracas reflected as the human population occupies and explores the environment, extending the city limits and facilitating the approach of man with wild vectors and reservoirs [25]. Whole communities can be affected by this trypanosomiasis due to the precarious and poorly structured rural or suburban houses, allowing the domiciliation of triatomines, the use of man and his domestic animals as a food source and subsequent peridomestic transmission from enzootic cycles. Vectors have managed to adapt and move from wild and semi-urban areas to cities $[17,18]$.

When the Chagas disease outbreak occurred in Chacao, Caracas, in 2007 [26], the researchers tracked the origin of the outbreak and the evidence led to imply that this was caused by drinking home-made guava juice prepared in a home of an urban neighborhood. The fruit juice was exposed overnight, allowing that infected triatomines, present in small remnants of the original vegetation near houses, fall into the liquid and contaminated the juice. This hypothesis is feasible because in the present investigation it was found that the construction of the home-made juice factory was unfinished. In the kitchen, one parrot stayed at the window and there was an aperture in the upper wall through which flying vectors could have entered.

Although the domiciliation of $P$. geniculatus, the vector of the area, was not confirmed, the community captured 77 adult specimens in outdoor areas of homes without coated walls. Further evidence has been adding eclecticism about the food source of this vector, with $84 \%$ of the specimens studied react to antisera rat / mouse / rabbit / dog / cat / bird, simultaneously, being rodents source the most frequently used.
The low participation of man as food source seems consistent with the predominant wild occupation of $P$. geniculatus, which occasionally moves to homes in search of food and / or attracted to light $[17,36,37]$. Paradoxically, the highest levels of parasite infection were found in insects fed on humans, followed by those fed on dogs, rabbit and rodents, which confirm the idea of the existence of zoonotic foci.

Since the infectivity blood meal index of blood in rats was $62.5 \%$, the prevalence of $T$. cruzi infected rats was $40 \%$ and the $42.1 \%$ of the studied triatomines prefer rat blood supply, this result suggest that rat is the primary reservoir in this micro focus.

With reference to the dog case, the data from the study did not allow confirming it as an important reservoir since despite a high infectivity blood meal index (66.6\%) and a $66 \%$ prevalence of infection in the triatomines studied, the number of dogs studied was low and so was the preference of P. geniculatus to feed on this animal (15.7\%). Some researchers have pointed out the domestic dog as an American trypanosomiasis sentinel, for his presence and seroreactivity in strictly domiciliary habitats, indicating the possible presence of a transmission cycle close to the region of the area of the animal, and a high rate of contact with these vectors, thus constituting an important epidemiological risk [38].

In epidemiological control programs in peridomestic and domestic habitats of endemic rural areas or in urban areas where the parasite is emerging [39], the surveillance of T. cruzi infection in dogs must be considered.

On the hill Waraira Repano (also known as Cerro El Ávila), very close to the focus studied, all the elements of the sylvatic cycle of T. cruzi, like "armadillos", and other small mammals are present, being the Didelphis marsupialis, a Caracas valley synanthropic reservoir, one of the most common, [5,16] with an important role in the transmission cycle in the capital city. However, the area's inhabitants did not report its presence and in the study of triatomines, it is not present as blood source, which suggests the participation of other mammals. P. geniculatus was 
not only present in the area under research, but additionally $50 \%$ of them carried T. cruzi, showing a possible zoophilia on domestic and synanthropic fauna. The considerable abundance of $R$. rattus, despite the low number of traps used, would indicate a high density, which benefits its offer as food source for reduviid bugs.

In El Tamarindo area, typical environment of the marginal areas of the city, which shows a precarious waste management, improvised housing and simplified wildlife as a result of the messy occupation of the environment, which benefits the access of domestic and peridomestic animals as food supply for triatomines. Rats, one of the most abundant mammals in the area, are highly prolific and are recognized as T. cruzi reservoirs. Rats and marsupials, both being synanthropic species, constitute an epidemiological risk to human population [5]. The transmission cycle described in the area where the fresh juice was prepared, seems to be adapted to the urban environment and maintained by $R$. rattus, P. geniculatus and sporadically Canis familiaris.

In the case of man, this transmission occurs through food contaminated with parasite from triatomines feces or fluids from infected mammals [28].

The simultaneously presence of acute infection by $T$. cruzi in the person who prepared the fresh juice that caused the oral transmission outbreak (102 people infected) in Caracas, along with the presence of genotype TC Id in isolates obtained from $P$. geniculatus and rats captured in El Tamarindo neighborhood $[40,41]$, connects this case with the oral transmission outbreak and suggests the existence of an outbreak initial focus at 6.7 $\mathrm{km}$ of distance from the school where the outbreak occurred, which would have gone unnoticed if this contingency would have not been exposed. Close contact of these triatomines to these synanthropic mammals infected with T. cruzi, could explain oral outbreaks in areas with no records of vector transmission. Caracas is a densely populated urban area non-endemic for Chagas disease, in which active transmission had not been registered since almost two decades [25,42].

The TcI lineage is found throughout America in both domestic and sylvatic cycles and it is believed to have evolved with arboreal Didelphimorphia (opossums) and vectors in the triatomine tribe Rhodniini [43]. In all parts of America, Didelphis spp. is a common reservoir for this lineage, although natural infection with TcI has been reported in a wide range of mammals. TcI is the only lineage reported from humans in North and Central America and the predominant lineage reported in human Chagas disease in the Amazon Basin in South America [44,45].

Parasite isolates were predominantly of haplotype TcId. Based on our results, the T. cruzi populations causing acute infections are those associated with the sylvatic foci and vectored by P. geniculatus. The DTU discrimination in the oral infection outbreak allowed us to highlight the significant impact of the DTUs from the sylvatic cycle, TcI. In the outbreak studied, which implies that oral transmission is a relevant epidemiological scenario that has emerged in the natural life cycle of T. cruzi. This suggests that, in areas where vectorial transmission has been interrupted, new acute cases of Chagas disease may arise as a potential problem in public health.
The results presented in this document lead to the consideration of the existence of an enzootic foci which could result in a zoonotic foci in areas with poor sanitation, poor surveillance and without species plague control programs and where there is no control in preparation and food distribution. These findings open up the review of paradigms in regards to oral transmission of Chagas disease, their spotlights enzootic as main route of transmission and how the anthropogenesis of Chagas disease and its history in Caracas could lead to its designation as a re-emerging parasitism.

The oral transmission converts Chagas disease into a foodborne disease. In this sense, prevention measures in both rural and urban areas should be addressed to raise awareness regarding the risk that infected triatomines, rats and Didelphis can contaminate food with their droppings and secretions. Prepared food and beverages should not stay out of the fridge, particularly at night. Washing should be routine for fruits and vegetables. Utensils such as cups, blenders, cutlery and pots should be checked before use. In school cafeterias, traditional drinks should be substituted by pasteurized packaged beverages. Fruit beverages whose preparation is not supervised should not be consumed.

\section{Ethical Considerations}

All procedures performed in the study were in accordance with the ethical standards of the ethics committee of the Institute of Tropical Medicine of the Central University of Venezuela in which the studies were conducted. Authorization: CEC-IMT $019 / 2010$.

\section{Acknowledgments}

The authors thank Arturo Muñoz-Calderon, for his help. We thank the people from the study communities for their kindness and patience to the study.

\section{References}

1. Hoare CA. The trypanosomes of mammals: a zoological monograph. Blackwell Scientific Publications. 1972:749.

2. Pinto Dias JC. Reseña histórica de los conocimientos sobre la enfermedad de Chagas y reflexiones sobre algunos aspectos políticos y socioeconómicos de la endemia en el contexto latinoamericano. Rev Fed Arg Cardiol 1988;17:121-132.

3. Dias JCP. Epidemiologia. En: Brener Z, Andrade Z, Barral-Netto M, editores. Trypanosoma cruzi e doença de Chagas. Guanabara Koogan Rio de Janeiro: 2000. p. 48-74.

4. Dias JC, Silveira AC, Schofield CJ. The impact of Chagas disease control in Latin America: a review. Mem Inst Oswaldo Cruz. 2002;97(5):60312.

5. Herrera L. A review of reservoirs of Trypanosoma (Schizotrypanum) cruzi (Chagas, 1909), the etiologic agent of Chagas disease. Bol Mal Salud Amb. 2010;50:3-15.

6. Forattini OP, da Rocha e Silva EO, Rabello EX, de Andrade JC, Rodrigues VL. [Ecological aspects of South American trypanosomiasis. XIII. Domestic enzootic potential in an area of occurrence of Panstrongylus megistus, under epidemiological surveillance]. Rev Saude Publica. 1978;12(4):417-24 
7. Noireau F, Vargas F, Bosseno MF, Breniere SF. Apparent trend to domesticity observed in Panstrongylus rufotuberculatus Champion, 1899 (Hemiptera: Reduviidae) In Bolivia. Research and Reviews in Parasitology. 1994;54(4):263-264

8. Herrera L, Urdaneta-Morales S. Synanthropic rodent reservoirs of Trypanosoma (Schizotrypanum) cruzi in the valley of Caracas, Venezuela. Rev Inst Med Trop Sao Paulo. 1997;39(5):279-82.

9. Reyes-Lugo M, Rodríguez-Acosta A. Domiciliation of the sylvatic Chagas disease vector Panstrongylus geniculatus Latreille, 1811. (Triatominae: Reduviidae) in Venezuela. Trans R Soc Trop Med Hyg 2000;94(5):508.

10. Feliciangeli MD, Carrasco H, Patterson JS, Suarez B, Martínez C, Medina M. Mixed domestic infestation by Rhodnius prolixus Stal, 1859 and Panstrongylus geniculatus Latreille, 1811, vector incrimination, and seroprevalence for Trypanosoma cruzi among inhabitants in El Guamito, Lara State, Venezuela. Am J Trop Med Hyg. 2004;71(4):501

11. Carrasco HJ, Torrellas A, García C, Segovia M, Feliciangeli MD. Risk of Trypanosoma cruzi I (Kinetoplastida: Trypanosomatidae) transmission by Panstrongylus geniculatus (Hemiptera: Reduviidae) in Caracas (Metropolitan District) and neighboring States, Venezuela Int J Parasitol. 2005;35(13):1379-84

12. Patterson JS, Barbosa SE, Feliciangeli DM. On the genus Panstrongylus Berg 1879: Evolution, ecology and epidemiological significance. Acta Trop. 2009;110(2-3):187-99. doi: 10.1016/j.actatropica.2008.09.008.

13. Quintini J. Nota sobre un nuevo Conorrhinus capturado en Caracas. Gac Med Caracas. 1920;27:171-172.

14. Deane MP, Lenzi HL, Jansen AM. Double development cycle of Trypanosoma cruzi in the opossum. Parasitol Today. 1986;2(5):146-7.

15. Urdaneta-Morales S, Nironi I. Trypanosoma cruzi in the anal glands of urban opossums. I--Isolation and experimental infections. Mem Inst Oswaldo Cruz. 1996;91(4):399-403.

16. Urdaneta-Morales S. Chagas disease: an emergent urban zoonosis The Caracas valley (Venezuela) as an epidemiological model. Front Public Health. 2014;2:265. doi: 10.3389/fpubh.2014.00265.

17. Reyes-Lugo M. P. geniculatus Latreille 1811 (Hemiptera: Reduviidae: triatomine), vector of Chagas disease in the home environment of north-central Venezuela. Rev Biomed 2009;20(3):180-205.

18. Carrasco HJ, Segovia M, Londoño JC, Ortegoza J, Rodríguez M, Martínez CE. Panstrongylus geniculatus and four other species of triatomine bug involved in the Trypanosoma cruzi enzootic cycle: high risk factors for Chagas disease transmission in the Metropolitan District of Caracas, Venezuela. Parasit Vectors. 2014;7:602. doi: 10.1186/s13071-0140602-7.

19. Diazgranados CA, Saavedra-Trujillo CH, Mantilla M, Valderrama SL, Alquichire C, Franco-Paredes C. Chagasic encephalitis in HIV patients: common presentation of an evolving epidemiological and clinical association. Lancet Infect Dis. 2009;9(5):324-30. doi: 10.1016/S14733099(09)70088-X.

20. Schmunis GA, Cruz JR. Safety of the blood supply in Latin America. Clin Microbiol Rev. 2005;18(1):12-29.

21. World Health Organization. New global effort to eliminate Chagas disease. Wkly Epidemiol Rec. 2007;82(28-29):259-60.

22. Beard CB, Pye G, Steurer FJ, Rodriguez R, Campman R, Peterson AT, et al. Chagas Disease in a domestic transmission cycle in Southern Texas, USA. Emerg Infect Dis. 2003;9(1):103-5.
23. Yabsley MJ, Noblet GP. Seroprevalence of Trypanosoma cruzi in raccoons from South Carolina and Georgia. J Wildl Dis. 2002;38(1):7583.

24. Alarcón de Noya B. Enfermedad de Chagas en Caracas. Salus. $2008 ; 12(1): 4-5$

25. Alarcón de Noya B, Díaz-Bello Z, Colmenares C, Zavala-Jaspe R, Mauriello L, Díaz MP, et al. Urban transmission of Chagas disease in Caracas, Venezuela: epidemiological, clinical and laboratorial aspects. Rev Biomed. 2009;20(3):158-164.

26. Alarcón de Noya B, Díaz-Bello Z, Colmenares C, Ruiz-Guevara R, Mauriello L, Zavala-Jaspe R, et al. Large urban outbreak of orally acquired acute Chagas Disease at a school in Caracas, Venezuela. J Infect Dis. 2010;201(9):1308-15. doi: 10.1086/651608.

27. Brener Z. Therapeutic activity and criterion of cure on mice experimentally infected with Trypanosoma cruzi. Rev Inst Med Trop Sao Paulo. 1962;4:389-96.

28. WHO. Control of Chagas disease. Second report of the WHO Expert Committee. WHO Technical Report Series 905. Geneva: World Health Organization. 2002;112.

29. Díaz-Bello Z, Zavala-Jaspe R, Tucci P, Colmenares C, Díaz M, Alarcón de Noya B. Evaluación del inmunoensayo enzimático sobre papel adherido a plástico para identificar fuentes de alimentación en triatominos y para la detección de Trypanosoma cruzi en xenodiagnóstico. Memorias XVII Congreso Latinoamericano de Parasitología 2005;60:195.

30.Voller A, Bidwell DE, Bartlett A. Enzyme immunoassays in diagnostic medicine. Theory and practice. Bull World Health Organ. 1976;53(1):55-65.

31. Díaz-Bello Z, Zavala-Jaspe R, Díaz-Villalobos M, Mauriello L, Maekelt A de Noya BA. [A confirmatory diagnosis of antibodies anti-Trypanosoma cruzi in donors referred by blood banks in Venezuela]. Invest Clin. 2008;49(2):141-50.

32. Souto RP, Fernandes O, Macedo AM, Campbell DA, Zingales B. DNA markers define two major phylogenetic lineages of Trypanosoma cruzi. Mol Biochem Parasitol. 1996;83(2):141-52.

33. Dias JC, Prata A, Correia D. Problems and perspectives for Chagas disease control: in search of a realistic analysis. Rev Soc Bras Med Trop. 2008;41(2):193-6.

34. Bastos CJ, Aras R, Mota G, Reis F, Dias JP, de Jesus RS, et al. Clinical outcomes of thirteen patients with acute Chagas disease acquired through oral transmission from two urban outbreaks in Northeastern Brazil. PLoS Negl Trop Dis. 2010;4(6):e711. doi: 10.1371/journal. pntd.0000711.

35. Rueda K, Trujillo JE, Carranza JC, Vallejo GA. [Oral transmission of Trypanosoma cruzi: a new epidemiological scenario for Chagas' disease in Colombia and other South American countries]. Biomedica. 2014;34(4):631-41. doi: 10.1590/S0120-41572014000400017.

36. Miles MA. The epidemiology of South American trypanosomiasis, biochemical and immunological approaches and their relevance to control. Trans R Soc Trop Med Hyg. 1983;77(1):5-23.

37. Reyes M. ¿Qué ha pasado en Venezuela cuando el ambiente urbano invade el hábitat natural de los triatominos vectores de la Enfermedad de Chagas? Vitae. 2011;1-8: http://vitae.ucv.ve

38. Roque AL, Xavier SC, da Rocha MG, Duarte AC, D'Andrea PS, Jansen AM. Trypanosoma cruzi transmission cycle among wild and domestic mammals in three areas of orally transmitted Chagas disease outbreaks. Am J Trop Med Hyg. 2008;79(5):742-9. 
39. Pineda V, Saldaña A, Monfante I, Santamaría A, Gottdenker NL, Yabsley MJ, et al. Prevalence of Trypanosome infections in dogs from Chagas disease endemic regions in Panama, Central America. Vet Parasitol. 2011;178(3-4):360-3. doi: 10.1016/j.vetpar.2010.12.043.

40. Díaz-Bello Z, Thomas MC, López MC, Zavala-Jaspe R, Noya O, DE Noya BA, et al. Trypanosoma cruzi genotyping supports a common source of infection in a school-related oral outbreak of acute Chagas disease in Venezuela. Epidemiol Infect. 2014;142(1):156-62. doi: 10.1017/ S0950268813000757.

41. Muñoz-Calderón A, Díaz-Bello Z, Valladares B, Noya O, López MC, Alarcón de Noya B, et al. Oral transmission of Chagas disease: typing of Trypanosoma cruzi from five outbreaks occurred in Venezuela shows multiclonal and common infections in patients, vectors and reservoirs. Infect Genet Evol. 2013;17:113-22. doi: 10.1016/j. meegid.2013.03.036.
42. Herrera L, Urdaneta-Morales S. Didelphis marsupialis: a primary reservoir of Trypanosoma cruzi in urban areas of Caracas, Venezuela. Ann Trop Med Parasitol. 1992;86(6):607-12.

43. Gaunt M, Miles M. The ecotopes and evolution of triatomine bugs (triatominae) and their associated trypanosomes. Mem Inst Oswaldo Cruz. 2000;95(4):557-65.

44. Iwagami M, Higo H, Miura S, Yanagi T, Tada I, Kano S. Molecular phylogeny of Trypanosoma cruzi from Central America (Guatemala) and a comparison with South American strains. Parasitol Res. 2007;102(1):129-34.

45. Roellig DM, Brown EL, Barnabé C, Tibayrenc M, Steurer FJ, Yabsley MJ. Molecular typing of Trypanosoma cruzi isolates, United States. Emerg Infect Dis. 2008;14(7):1123-5. doi: 10.3201/eid1407.080175. 